\title{
Air pollution and population health: a global challenge
}

\author{
Bingheng Chen $\cdot$ Haidong Kan
}

Received: 14 September 2007 / Accepted: 18 October 2007/Published online: 28 February 2008

(C) The Japanese Society for Hygiene 2008

\begin{abstract}
Air pollution and population health" is one of the most important environmental and public health issues. Economic development, urbanization, energy consumption, transportation/motorization, and rapid population growth are major driving forces of air pollution in large cities, especially in megacities. Air pollution levels in developed countries have been decreasing dramatically in recent decades. However, in developing countries and in countries in transition, air pollution levels are still at relatively high levels, though the levels have been gradually decreasing or have remained stable during rapid economic development. In recent years, several hundred epidemiological studies have emerged showing adverse health effects associated with short-term and long-term exposure to air pollutants. Time-series studies conducted in Asian cities also showed similar health effects on mortality associated with exposure to particulate matter (PM), sulfur dioxide $\left(\mathrm{SO}_{2}\right)$, nitrogen dioxide $\left(\mathrm{NO}_{2}\right)$ and ozone $\left(\mathrm{O}_{3}\right)$ to those explored in Europe and North America. The World Health Organization (WHO) published the "WHO Air Quality Guidelines (AQGs), Global Update" in 2006. These updated AQGs provide much stricter guidelines for $\mathrm{PM}, \mathrm{NO}_{2}, \mathrm{SO}_{2}$ and $\mathrm{O}_{3}$. Considering that current air pollution levels are much higher than the WHO-recommended AQGs, interim targets for these four air pollutants are also recommended for member states, especially for developing countries in setting their country-specific air quality standards. In conclusion, ambient air pollution is a health hazard. It is more important in Asian developing countries
\end{abstract}

B. Chen $(\bowtie) \cdot$ H. Kan

Department of Environmental Health, School of Public Health, Fudan University, 138 Yi-Xue-Yuan Road, Shanghai 200032, China

e-mail: bhchen@shmu.edu.cn within the context of pollution level and population density. Improving air quality has substantial, measurable and important public health benefits.

Keywords Air pollution - Health effects .

Time-series study · Risk assessment .

WHO Air Quality Guidelines

\section{Introduction}

Clean air is one of the basic requirements of human health and well-being. However, during the process of economic development, air pollution has been and continues to be a significant health hazard worldwide. The driving forces of air pollution include economic development, urbanization, energy consumption, transportation and motorization, as well as increase of urban population. Exposure to air pollutants is a problem of increasing concern due to the diversity of the pollutants in question, adverse effects observed in a broad range of air pollution levels, and the vast number of people at risk. The effects of air pollution can sometimes be observed even when the pollution level is below the level indicated by air quality guidelines. Individuals differ widely in genetic predisposition and physiological response to pollutants. Young children, the elderly, persons with predisposed diseases, such as cardiovascular and pulmonary diseases, and workers in certain industries may be at a higher risk owing to their increased biological sensitivities and different exposure patterns. The most common ambient air pollutants encountered in our daily life are particulate matter (PM), sulfur dioxide $\left(\mathrm{SO}_{2}\right)$, nitrogen dioxide $\left(\mathrm{NO}_{2}\right)$, ozone $\left(\mathrm{O}_{3}\right)$, carbon monoxide $(\mathrm{CO})$, and carbon dioxide $\left(\mathrm{CO}_{2}\right)$. The environmental Kuznets curve (EKC) can be used to study the relationship 


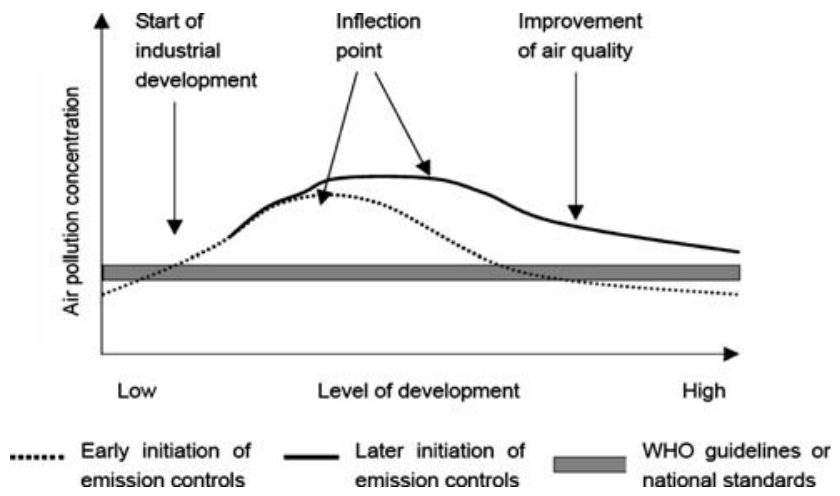

Fig. 1 Environmental Kuznets curve (EKC)

between economic development and air pollution levels. During the early stage of economic development, air pollution level is generally low. However, when economic development reaches an intermediate stage, air pollution concentration levels tend to increase appreciably or even rise sharply if no effective ameliorating measures are taken. It might then reach an inflexion point later at a higher development stage due to better environmental awareness and relevant control measures taken in protecting the environment (Fig. 1). As zero risk is neither practical nor necessary, it is crucial to set appropriate air pollutant guidelines for air pollution management to meet.

\section{Global trend in air pollution levels}

Particulate matter (PM), $\mathrm{SO}_{2}, \mathrm{NO}_{2}$ and $\mathrm{O}_{3}$ are considered classical/traditional air pollutants, and commonly used as indicator pollutants for fuel combustion and traffic-related air pollution. In the middle of the twentieth century, total suspended particulate (TSP) levels were very high in some large cities. For instance, during the London episode in 1952, ambient TSP and $\mathrm{SO}_{2}$ levels reached several thousands of micrograms per cubic meter $\left(\mu \mathrm{g} / \mathrm{m}^{3}\right.$; [1]). In Shenyang, a heavy-industry city in north-eastern China, TSP and $\mathrm{SO}_{2}$ levels were in the range of hundreds to thousands of $\mu \mathrm{g} / \mathrm{m}^{3}$ [2]. After decades of effort in air pollution management control, air pollutant levels in most developed countries have been decreasing dramatically. However, in many developing countries, as well as countries in transition, though air pollution levels have been slightly decreasing or has remained stable, they are still higher than those in developed countries. The World Health Organization has summarized the annual average concentrations of particulate matter less than $10 \mu \mathrm{m}$ in aerodynamic diameter $\left(\mathrm{PM}_{10}\right), \mathrm{NO}_{2}$ and $\mathrm{SO}_{2}$, as well as the $1 \mathrm{~h}$ average maximum concentrations of $\mathrm{O}_{3}$ for different regions in the world [3] (Table 1). In most European and North American cities, the $\mathrm{PM}_{10}$ annual average
Table 1 Ranges of annual average concentrations of $\mathrm{PM}_{10}, \mathrm{NO}_{2}$, $\mathrm{SO}_{2}$ and $1 \mathrm{~h}$ average maximum concentrations of ozone for different regions, based on selection of urban data $\left(\mu \mathrm{g} / \mathrm{m}^{3}\right)$

\begin{tabular}{|c|c|c|c|c|}
\hline \multirow[t]{2}{*}{ Region } & \multicolumn{3}{|c|}{ Annual average concentration } & \multirow{2}{*}{$\begin{array}{l}\text { Ozone ( } 1 \mathrm{~h} \\
\text { maximum } \\
\text { concentration) }\end{array}$} \\
\hline & $\mathrm{PM}_{10}$ & $\begin{array}{l}\text { Nitrogen } \\
\text { dioxide }\end{array}$ & $\begin{array}{l}\text { Sulfur } \\
\text { dioxide }\end{array}$ & \\
\hline Africa & $40-150$ & $35-65$ & $10-100$ & $120-300$ \\
\hline Asia & $35-220$ & $20-75$ & $6-65$ & $100-250$ \\
\hline $\begin{array}{l}\text { Australia/ } \\
\text { New Zealand }\end{array}$ & $28-127$ & $11-28$ & $3-17$ & $120-310$ \\
\hline $\begin{array}{l}\text { Canada/ } \\
\text { United States }\end{array}$ & $20-60$ & $35-70$ & $9-35$ & $150-380$ \\
\hline Europe & $20-70$ & $18-57$ & $8-36$ & $150-350$ \\
\hline Latin America & $30-129$ & $30-82$ & $40-70$ & $200-600$ \\
\hline
\end{tabular}

Cited from [40]

concentration levels are generally lower than $50 \mu \mathrm{g} / \mathrm{m}^{3}$. The highest levels of $\mathrm{PM}_{10}$ are found in Asia, Africa and Latin America. In Asia, PM is still the major and most important air pollutant, though in some large cities, such as certain cities in China, a slight decrease in $\mathrm{PM}_{10}$ levels has been noted during the economic development over the last few decades [4].

$\mathrm{SO}_{2}$ levels have been decreasing in most parts of the world. They have declined substantially in the United States and Europe in particular. In some Asian cities, (e.g., Bangkok, New Delhi, and Jakarta), the ambient $\mathrm{SO}_{2}$ levels are low due to the low sulfur content of the fuel used there. On the other hand, in Chinese cities, although the $\mathrm{SO}_{2}$ level has declined quite substantially, it is still relatively high. In larger cities in Latin America and Africa, there has also been a moderate decline in $\mathrm{SO}_{2}$ levels [3].

On the other hand, such a tendency has not been observed for traffic-related air pollutants, i.e., $\mathrm{NO}_{2}$ and $\mathrm{O}_{3}$. To the contrary, in countries in transition, levels of $\mathrm{NO}_{2}$ and $\mathrm{O}_{3}$ tend to increase due to the increased number of motor vehicles. Megacities where annual average $\mathrm{NO}_{2}$ exceeded the WHO air quality criteria of $40 \mu \mathrm{g} / \mathrm{m}^{3}$ were Beijing, Shanghai, Tokyo, Osaka, New York, Los Angeles, San Paulo and Mexico, while in New Delhi, Mumbai and Calcutta the annual average $\mathrm{NO}_{2}$ concentrations were lower than $40 \mu \mathrm{g} / \mathrm{m}^{3}$ [5]. Ozone and some of its precursors are transported long distances and across borders (transboundary movements) in the atmosphere, and so they can be considered to be a regional and even a global problem. With regard to its adverse health effects, atmospheric ozone concentrations are usually assessed as $1 \mathrm{~h}$ maximum or maximum $8 \mathrm{~h}$ average concentrations because they are closely associated with sunlight. The highest levels of ozone and $\mathrm{NO}_{2}$ are found in Latin America and in some large cities of other developed countries. 


\section{Adverse health effects associated with exposure to air pollution}

Exposure to ambient air pollution has been associated with a series of adverse health effects, ranging from subclinical effects, physiological changes in pulmonary functions and the cardiovascular system, to clinical symptoms, outpatient and emergency-room visits, hospital admissions, and finally to premature death. Most of the recent evidence focuses on respiratory and cardiovascular effects associated with exposure to short-term and long-term exposure to air pollution. High-risk subgroups include young children, the elderly, persons with predisposed diseases, and persons with low socioeconomic status (SES).

The increased risk of air pollution-related health effects seems to be relatively low, generally in the range of only a few percent. However, the total number of people affected worldwide is quite significant. More importantly, most state-of-the-art epidemiological studies using sophisticated statistical tools have shown that the pollutant concentration associated with increased risk is quite low. In other words, even when the WHO 2000 Air Quality Guidelines and/or individual country-specific air quality standards are met, the increased health risk still exists.

Health effects of short-term exposure to air pollutants

Epidemiological studies are generally not available for most environmental chemicals. However, in recent years many epidemiological studies, time-series studies in particular, have emerged that show statistically significant associations between exposure to classical air pollutants and adverse health effects including mortality and morbidity. Nevertheless, more evidence is needed to establish a causal relationship, and the underlying mechanism needs to be further explored.

The epidemiological studies used to explore the relationship between changes in air pollution levels over the short term and changes in various health endpoints are time-series studies, panel studies and case-crossover studies. In time-series studies, repeated observations of exposure and health outcomes (daily mortality or morbidity) are made over time within the same study population in a geographically defined area. The analysis centers on comparing variations in exposure status over time with changes in health outcomes over time. A time-series study based on aggregate data is essentially a temporal comparison study that examines an association between a variable exposure and a variable health outcome. Since observations are made within the same population, the influence of many confounding factors can thus be avoided. Access to air pollution data and death records and other health data has been increasing in many cities worldwide, so hundreds of time-series studies exploring short-term exposure effects of air pollution have emerged.

\section{PM}

Many time-series studies have explored the acute health effects associated with short-term exposure to airborne particulates [6]. $\mathrm{PM}_{10}$ is used as an indicator for airborne particulates as there are extensive monitoring data for $\mathrm{PM}_{10}$ throughout the world. Substantial evidence shows that PM exposure is linked to a variety of adverse effects on mortality (nonaccidental all-cause mortality, cardiovascular and respiratory mortality) and morbidity (hospital admissions, outpatient and emergency-room visits, asthma attacks, acute respiratory infection of young children, etc.). Risk for acute events, including myocardial infarction and stroke, has been assessed [7]. Risk for birth outcomes has also been studied, but the evidence is still inconclusive based on the currently available data [8,9].

The evidence of airborne PM and adverse health effects is consistent in various cities, both in developed and developing countries. Most time-series studies show a positive association between PM concentration and an increased risk for total and cause-specific mortality. A WHO task group summarized the relative risk estimates (and 95\% confidence interval) for a $10 \mu \mathrm{g} / \mathrm{m}^{3} \mathrm{PM}_{10}$ increase for all-cause mortality of all ages, for respiratory mortality of all ages, and for cardiovascular mortality of all ages. They are 1.006 (1.004-1.008), 1.013 (1.005-1.020), and 1.009 (1.005-1.013), respectively. It can be seen that the risk estimates for respiratory and cardiovascular mortality are larger than that for all-cause mortality. These summarized data were based on the results for 33, 18 and 17 European cities [10]. In another meta-analysis, an increase of $10 \mu \mathrm{g} / \mathrm{m}^{3} \mathrm{PM}_{10}$ is associated with an increase in all-cause mortality of $0.46,0.62$, and $0.49 \%$ in the United States (30 city studies), Europe (21 city studies), and Asia (4 city studies), respectively [11].

In some studies positive associations between fine particles $\left(\mathrm{PM}_{2.5}\right)$ and daily mortality were not observed. A study conducted in a district of Chongqing in China showed no positive association between daily ambient $\mathrm{PM}_{2.5}$ concentration and daily mortality. However, a positive association was found between daily ambient $\mathrm{SO}_{2}$ concentration and daily mortality, especially respiratory and cardiovascular mortality. When $\mathrm{PM}_{2.5}$ was controlled in the model, the association found between daily ambient $\mathrm{SO}_{2}$ and mortality remained unchanged [12].

Most of the time-series studies have shown an increased risk with exposure to air pollution. However, associations 
observed in time-series studies could only reflect the situation that occurs just a short period prior to the time of death, and mostly among elderly people already suffering from respiratory or cardiovascular diseases. Therefore the association observed in time-series studies may not necessarily imply a significant health effect for the total population. Nevertheless, there is little evidence to suggest a threshold below which no adverse health effects would be anticipated.

In comparison with studies on mortality, there are fewer epidemiological studies on the association between morbidity and ambient air pollution levels. Hwang et al. studied the effects of air pollution on daily clinic visits for lower respiratory tract illness in Taiwan during 1998. The study included 50 townships and city districts in Taiwan where ambient air monitoring stations of the Taiwan Air Quality Monitoring Network are located. It was found that $\mathrm{PM}_{10}, \mathrm{NO}_{2}, \mathrm{CO}$, and $\mathrm{SO}_{2}$ showed significant effects on daily clinic visits due to lower respiratory tract illness including acute bronchitis, acute bronchiolitis and pneumonia. In contrast, daily clinic visit rates were found not associated with maximum hourly ozone levels. People aged 65 years and over are more susceptible to the effects of $\mathrm{PM}_{10}$ than other age groups [13]. In another paper, Hwang et al. reported that $\mathrm{NO}_{2}$ exposure was related to increased schoolchildren absence due to respiratory illness in the subsequent three days [14].

In order to better understand the underlying mechanism of adverse effects associated with exposure to air pollutants found from many epidemiological studies, several plausible mechanistic pathways have been described [15]. Toxicological studies have shown that airborne particulates exert their effects on health mainly through inflammatory and oxidative stress-related processes. PM may have direct effects on the respiratory tract, including production of an inflammatory response, exacerbation of existing airway disease or impairment of pulmonary defense mechanisms. Inflammation is an important mechanism for producing many of the health effects of PM. Inhaled PM may increase production of antigenspecific immunoglobulins, alter airway reactivity to antigen, or enhance susceptibility of the lungs to microbial infection. There are also extrapulmonary effects of PM. One potential pathway is via systemic transport of cytokines produced in the lungs by an inflammatory response. Another potential pathway is through unfavorable effects on coagulation properties that lead to increased risk of stroke or myocardial infarction. There is also the possibility that PM may have a direct effect on the heart, resulting in changes in blood pressure, heart rate, and heart rate variability.
$\mathrm{SO}_{2}$

As mentioned above, many time-series studies have been conducted to explore the association between PM and daily mortality and morbidity; about $60 \%$ of these studies also examined the health impacts of $\mathrm{SO}_{2}$. Associations between $\mathrm{SO}_{2}$ exposure and daily mortality (including all-cause, cardiovascular and pulmonary mortality) were found in most of these studies, but the consistency of association between $\mathrm{SO}_{2}$ exposure with daily mortality appeared to be less than that for PM. On the other hand, some studies found that the association of $\mathrm{SO}_{2}$ and mortality was stronger than that of PM [16]. Some researchers argued that $\mathrm{SO}_{2}$ might serve as a "surrogate" for urban air pollution from fossil fuel combustion [17].

Associations between emergency hospital admissions for asthma and $\mathrm{SO}_{2}$ have been reported in some studies, but not in others [18]. Likewise, associations between hospital admissions for chronic obstructive pulmonary disease (COPD) and $\mathrm{SO}_{2}$ were found to be significantly positive in some studies, but not in others [19]. Association between $\mathrm{SO}_{2}$ and cardiac disease hospital admissions was found both in London and Hong Kong despite their differences in climate and ethnicity [20]. A meta-analysis analyzed the time-series studies performed in Asia on $\mathrm{SO}_{2}$ and respiratory and cardiovascular hospital admissions, in which positive associations were also found [11]. However, it could not be concluded whether $\mathrm{SO}_{2}$ per se is positively correlated with hospital admissions or acts as a surrogate for a mixture of urban air pollutants.

A time-series analysis comparing daily rates of SIDS (sudden infant death syndrome) and daily concentrations of air pollution during a 16-year period was conducted in 12 Canadian cities. The results showed that ambient $\mathrm{SO}_{2}$ and $\mathrm{NO}_{2}$ might be important risk factors for SIDS [21].

$\mathrm{NO}_{2}$

Many time-series studies have been conducted to explore the association between $\mathrm{NO}_{2}$ exposure and daily mortality. $\mathrm{NO}_{2}$ daily concentrations are found to be significantly associated with increased all-cause, cardiovascular and respiratory mortality. A meta-analysis on daily mortality and $24 \mathrm{~h} \mathrm{NO}_{2}$ levels $\left(20.4-103.3 \mu \mathrm{g} / \mathrm{m}^{3}\right)$ indicated that the overall effect estimate from the single pollutant model for all-cause mortality was $2.8 \%$ per $45 \mu \mathrm{g} / \mathrm{m}^{3}$ increase of $\mathrm{NO}_{2}$, which fell to $0.9 \%$ in multipollutant models, including particles [22]. The European APHEA-1 (Air Pollution and Health, a European Approach) study found a $1.3 \%$ increase in daily deaths (95\% CI $0.9-1.8)$ per $50 \mu \mathrm{g} / \mathrm{m}^{3}$ increase of $\mathrm{NO}_{2}$ (1 $\mathrm{h}$ maximum) [23]. The effect remained 
statistically significant after adjusting for black smoke. The APHEA-2 study found that PM effects on daily mortality were stronger in areas with high levels of $\mathrm{NO}_{2}$ [24]. The US National Morbidity and Mortality Air Pollution Study (NMMAPS) showed that daily mortality increased from 0.3 to about $0.4 \%$ per $10 \mathrm{ppb}\left(18.8 \mu \mathrm{g} / \mathrm{m}^{3}\right)$ increase of $\mathrm{NO}_{2}$. Although a causal association cannot be indicated, short-term variations of $\mathrm{NO}_{2}$ clearly predict an increase in daily mortality $[25,26]$.

The results of most of the time-series studies on $\mathrm{NO}_{2}$ and hospital admissions/emergency room visits for respiratory and cardiovascular diseases as well as doctor visits for asthma in children show an independent $\mathrm{NO}_{2}$ effect. Controlling for other pollutants lowers the effect estimates at times, and at other times makes them statistically insignificant [27]. In some studies, $\mathrm{NO}_{2}$, rather than PM, was found to be associated with asthma hospital admissions [28]. An effect of $\mathrm{NO}_{2}$ has been noted in most panel studies evaluating aggravation of asthma in children, showing a clear effect of $\mathrm{NO}_{2}$ on incidence of viral infections among asthmatics [29].

Health risks from nitrogen oxides may result from $\mathrm{NO}_{2}$ per se or its products, including $\mathrm{O}_{3}$ and secondary fine particles. It is difficult to determine whether the independent effects observed for $\mathrm{NO}_{2}$ and $\mathrm{PM}$ are really effects of the gaseous pollutant $\mathrm{NO}_{2}$, or independent effects of regionally transported particles and locally produced fine and ultrafine particles. However, $\mathrm{NO}_{2}$ levels are generally considered a reasonable indicator of exposure to trafficrelated emissions.

$\mathrm{O}_{3}$

Combined evidence from time-series studies show positive associations between daily mortality and ozone levels, independent of the effects of particulate matter. Risk estimates on ozone related mortality are higher in the warmer season. Temperature plays a significant role in the magnitude of the coefficients [30, 31, 32]. A meta-analysis on 95 US urban communities studies showed that a $20 \mu \mathrm{g} / \mathrm{m}^{3}$ increase in ozone was associated with a $0.52 \%$ increase in total mortality and a $0.64 \%$ increase in cardiovascular and respiratory mortality [33]. In another meta-analysis of 144 effect estimates from 39 time-series studies, a $10 \mu \mathrm{g} / \mathrm{m}^{3}$ increase in ozone was associated with a $0.87 \%(95 \% \mathrm{CI}$ 0.55-1.18) increase in all-cause mortality for all seasons and a $1.34 \%$ increase (95\% CI $0.45-3.17$ ) in the warmer season. For cardiovascular disease, the same increment of ozone was associated with a $1.11 \%$ (95\% CI 0.68-1.53) increase during all seasons and a $2.45 \%$ increase $(95 \% \mathrm{CI}$ 0.88-4.1) in the warmer season [31]. Ito et al. [32] conducted a meta-analysis of 43 studies; each $20 \mu \mathrm{g} / \mathrm{m}^{3}$ increase in $1 \mathrm{~h}$ maximum ozone was associated with a $0.39 \%$ increase (95\% CI 0.26-0.51) in all-cause mortality. There was no appreciable modification by including PM as copollutant in the models. Effects were larger for the warmer season.

In Asia, ozone associated with mortality due to stroke was reported in Seoul; an increase of $34 \mu \mathrm{g} / \mathrm{m}^{3}$ ozone had a RR 1.06 (95\% CI 1.02-1.10) on stroke mortality [34]. In a Chinese study, a significant effect of ozone on daily mortality was found in Shanghai; furthermore, $\mathrm{O}_{3}$ pollution was found to have stronger health effects in the cold than in the warm season in the city [35].

There is no clear evidence of a threshold for ozone. Time-series studies have shown effects at ozone concentrations as low as $75 \mu \mathrm{g} / \mathrm{m}^{3}(1 \mathrm{~h}$ mean) [31]. Combined evidence shows that ozone exposure is significantly associated with increase in morbidity. The most common health end-points are school absenteeism, hospital or emergency room admissions for asthma, respiratory infections, and exacerbation of chronic airway diseases. Children, elderly people, asthmatics and those with chronic obstructive airway diseases are more sensitive to ozone exposure. Effects of ozone on respiratory hospital admissions seem stronger during the warmer season.

Health effects of long-term exposure to air pollutants

There was evidence showing chronic adverse health effects associated with long-term exposure to air pollution, especially PM. Two long-term exposure studies, i.e., the US American Cancer Society (ACS) study and Harvard Six-City cohort study, reported associations between longterm exposure to $\mathrm{PM}_{2.5}$ and mortality. In the ACS Cancer Prevention Study II (CPS-II), a prospective cohort study, 500,000 adults linked with air pollution data from 1982 to 1998 were followed. Confounders including cigarette smoking, BMI, diet, occupational exposure, age, sex, race, education, and alcohol were controlled. A $10 \mu \mathrm{g} / \mathrm{m}^{3}$ increase of $\mathrm{PM}_{2.5}$ was associated with approximately 4,6 and $8 \%$ increases in the risk of all-cause, cardiopulmonary, and lung cancer mortality, respectively. Coarse particle fraction $\left(\mathrm{PM}_{2.5-15}\right)$ and TSP (total suspended particulates) were not consistently associated with mortality. Thresholds were not apparent in these studies. However, a $\mathrm{PM}_{2.5}$ annual mean level of $10 \mu \mathrm{g} / \mathrm{m}^{3}$ is found to be the lowest level at which all-cause, cardiopulmonary and lung cancer mortality have been shown to increase with more than $95 \%$ confidence in response to $\mathrm{PM}_{2.5}$. Although adverse health effects cannot be entirely ruled out, even at such low level, these levels are expected to effectively reduce the health risks [36]. The US Harvard six-city prospective cohort study showed that mortality rates were most strongly 
associated with cigarette smoking. After adjusting for smoking and other risk factors, statistically significant associations between air pollution and mortality were observed. The adjusted mortality rate ratio for the most polluted cities as compared with the least polluted cities was 1.26 (95\% CI 1.08-1.47). Air pollution was positively associated with death from lung cancer and cardiopulmonary disease but not with death from other causes. Mortality was most strongly associated with fine particulates, including sulfates [37]. It was thus concluded that long-term exposure to fine particles $\left(\mathrm{PM}_{2.5}\right)$ and sulfur oxide-related air pollution is an important environmental risk factor for cardiopulmonary and lung cancer mortality.

Long-term exposure to fine particles $\left(\mathrm{PM}_{2.5}\right)$ has been linked to incidence of cardiovascular disease and death among postmenopausal women [38]. The authors studied 65,893 postmenopausal women without previous cardiovascular disease in 36 US metropolitan areas from 1994 to 1998, with a median follow-up of six years. Hazard ratios were estimated for the first cardiovascular event, adjusting for age, race or ethnic group, smoking status, educational level, household income, body-mass index, diabetes, hypertension, and hypercholesterolemia. A total of 1,816 women had one or more fatal or nonfatal cardiovascular events, including death from coronary heart disease or cerebrovascular disease, coronary revascularization, myocardial infarction, and stroke. Each increase of $10 \mu \mathrm{g} / \mathrm{m}^{3}$ of $\mathrm{PM}_{2.5}$ was associated with a $24 \%$ increase in the risk of a cardiovascular event (hazard ratio 1.24 ; 95\% CI 1.09-1.41) and a $76 \%$ increase in the risk of death from cardiovascular disease (hazard ratio $1.76 ; 95 \%$ CI 1.25-2.47). The risk of cerebrovascular events was also associated with increased levels of $\mathrm{PM}_{2.5}$ (hazard ratio 1.35 ; 95\% CI 1.08-1.68).

\section{Causal evidence from intervention study}

Numerous studies have shown evidence for the association of air pollution with increased daily death. However, there is little direct evidence that diminished particulate or gaseous air pollution levels could lead to reductions in death rates or increase in life-expectancy. In other words, it shows an association rather than a causal relation in the context of air pollution level and death rates. Two citywide air pollution regulations were put into practice during a short period in Hong Kong and Dublin. The direct and immediate health benefit of decreased air pollution level provides convincing evidence supporting a causal relationship between air pollution level and death rates.

The Irish Government banned the sale of bituminous coal within the city of Dublin on 1 September 1990, as Dublin's air quality deteriorated in the 1980s after using cheaper bituminous coal for domestic heating. After the ban on coal sales, average black smoke concentrations in Dublin declined by $35.6 \mu \mathrm{g} / \mathrm{m}^{3} \quad(70 \%)$. Non-trauma, respiratory, and cardiovascular death rates were compared for 72 months before and after the ban of coal sales. Adjusted non-trauma death rates decreased by $5.7 \%(95 \%$ CI $4-7, P<0.0001)$, respiratory deaths by $15.5 \%(12-19$, $P<0.0001)$, and cardiovascular deaths by $10.3 \%(8-13$, $P<0.0001)$. About 116 fewer respiratory deaths and 243 fewer cardiovascular deaths were seen per year in Dublin after the ban [39].

In Hong Kong, the sulfur content of fuels used by all power plants and vehicles was reduced to $0.5 \%$ over a weekend in July 1990. The ambient air $\mathrm{SO}_{2}$ levels declined from 44 to $21 \mu \mathrm{g} / \mathrm{m}^{3}$, about $50 \%$ decrease, while $\mathrm{PM}_{10}$, $\mathrm{NO}_{2}$ and ozone levels did not change. The decreased $\mathrm{SO}_{2}$ level in ambient air is associated with a reduction in number of deaths among people residing there. All-cause mortality decreased by $2.1 \%$ (about 600 deaths per year associated with 10,268 person-years of life per year), respiratory disease mortality decreased by $3.9 \%$, and cardiovascular disease mortality decreased by $2.0 \%$. Average gain in life expectancy for females per year of exposure to the decreased $\mathrm{SO}_{2}$ level was 20 days, for males 41 days. In this intervention study it was found that $\mathrm{SO}_{2}$ exposure was consistently associated with mortality, while $\mathrm{PM}_{10}$ exposure was only marginally associated with mortality [16]. In these two intervention studies the reduced black smoke and $\mathrm{SO}_{2}$ levels leading to reductions in daily mortality supported a causal relationship between air pollutant exposure and daily mortality.

\section{WHO Air Quality Guidelines}

The WHO Air Quality Guidelines are an international reference on the adverse effects of exposure to air pollutants on human health. WHO summarized the scientific knowledge on health hazards related to air pollutants, providing risk estimates for exposure to air pollutants and recommending air quality guidelines for member states to develop their own national air quality standards. The first edition of the WHO Air Quality Guidelines for Europe (WHO AQG) was published in 1987, and was updated in 2000. As numerous new data have emerged in recent years, it was decided to revise and update the second version. The latest global updated version of the WHO AQG was published in 2006 (Table 2) [40]. This updated AQG focused on four classical air pollutants, namely particulate matter, ozone, nitrogen dioxide and sulfur dioxide. As numerous data have emerged recently that show that even at low concentration levels adverse health effects still exist and that no clear threshold value can be established, in order to protect human health from air pollution the updated air 
Table 2 Global updated WHO Air Quality Guidelines

\begin{tabular}{llc}
\hline Pollutants & Averaging time & $\begin{array}{c}\text { AQG values } \\
\left(\mu \mathrm{g} / \mathrm{m}^{3}\right)\end{array}$ \\
\hline Particulate matter & & \\
$\mathrm{PM}_{2.5}$ & 1 year & 10 \\
& 24 h (99th percentile) & 25 \\
$\mathrm{PM}_{10}$ & 1 year & 20 \\
& 24 h (99th percentile) & 50 \\
Ozone $\mathrm{O}_{3}$ & 8 h daily maximum & 100 \\
Nitrogen dioxide $\mathrm{NO}_{2}$ & 1 year & 40 \\
& $1 \mathrm{~h}$ & 100 \\
Sulfur dioxide $\mathrm{SO}_{2}$ & $24 \mathrm{~h}$ & 20 \\
& $10 \mathrm{~min}$ & 500 \\
\hline
\end{tabular}

quality guidelines are much stricter than those recommended in the second version, published in 2000. Considering the actual high air pollution levels in most developing countries, it is not feasible, indeed virtually impossible, to meet the strict criteria. Thus the WHO further provides interim targets for these four pollutants for decision makers of member states so that they can set their own goals for controlling air pollution in order to protect human health to some extent at various development stages. Meantime, it was emphasized that the updated AQG suits every person in every country.

\section{Summary}

In conclusion, ambient air pollution is a health hazard. It is a global challenge, as evidence shows that adverse effects still exist even at relatively low air pollutant concentrations, and so no threshold values for classical air pollutants can be established based on the available data. It is more important in Asian developing countries due to the severe pollution levels and high population densities associated with them. Improving air quality has substantial, measurable and important public health benefits. Efforts should be made and goals set in order to control air pollution in every country.

\section{References}

1. Davis DL, Bell ML, Fletcher T. A look back at the London smog of 1952 and the half century since-Guest Editorials. Environ Health Perspect. 2002;110(12):A734.

2. Cao SR, Chen BH. Advancement on the research on the toxicity of atmospheric suspended particulates. In: Hong CJ, editors. Advancement of environmental health, vol. 1. Beijing: People's Health Publishing; 1987. p. 34-50 (in Chinese).

3. Sivertsen B. Global ambient air pollution concentrations, trends. In: World Health Organization, editor. Air Quality Guidelines,
Global Update 2005. Copenhagen: WHO Regional Office for Europe; 2006. p. 31-59.

4. Hao J, Wang L. Improving urban air quality in China: Beijing case study. J Air Waste Manag Assoc. 2005;55(9):1298-305.

5. Gan L. Globalization of the automobile industry in China: dynamics and barriers in the greening of road transportation. Energy Policy. 2003;31(6):537-51.

6. Brunekreef B, Holgate ST. Air pollution and health. Lancet. 2002;360:1233-42.

7. Peters A, Dockery DW, Muller JE, et al. Increased particulate air pollution and the triggering of myocardial infarction. Circulation. 2001;103:2810-5.

8. Leem JH, Kaplan BM, Shim YK, et al. Exposures to air pollutants during pregnancy and preterm delivery. Environ Health Perspect. 2006;114(6):905-10.

9. Maisonet M, Correa A, Misra D, Jaakkola JJ. A review of the literature on the effects of ambient air pollution on fetal growth. Environ Res. 2004;95(1):106-15.

10. Anderson RH, et al. Meta-analysis of time-series studies and panel studies of particulate matter (PM) and ozone (O3). Report of a WHO task group. Copenhagen: WHO Regional Office for Europe; 2004. http://www.euro.who.int/document/e82792.pdf. Accessed 27 Sept 2006.

11. Health Effects Institute (HEI). Health effects of outdoor air pollution in developing countries of Asia: a literature review. Boston: Health Effects Institute; 2004.

12. Venners SA, Wang $\mathrm{B}, \mathrm{Xu} \mathrm{Z}$, et al. Particulate matter, sulfur dioxide, and daily mortality in Chongqing, China. Environ Health Perspect. 2003;111:562-7.

13. Hwang JS, Chen YJ, Wang JD, et al. Subject-domain approach to the study of air pollution effects on schoolchildren's illness absence. Am J Epidemiol. 2000;152(1):67-74.

14. Hwang JS, Chan CC. Effects of air pollution on daily clinic visits for lower respiratory tract illness. Am $\mathrm{J}$ Epidemiol. 2002;155(1):1-10.

15. Brook RD, Franklin B, Cascio W, et al. Air pollution and cardiovascular disease. A statement for healthcare professionals from the expert panel on population and prevention science of the American Heart Association. Circulation. 2004;109:2655-71.

16. Hedley AJ, Wong CM, Thach TQ, et al. Cardiorespiratory and all-cause mortality after restrictions on sulfur content of fuel in Hong Kong: an intervention study. Lancet. 2002;360:1646-52.

17. Buringh E, Fischer P, Hoek G. Is $\mathrm{SO}_{2}$ a causative factor for the PM-associated mortality risks in the Netherlands? Inhal Toxicol. 2000;12(suppl 1):55-60.

18. Sunyer J, et al. Urban air pollution and emergency room admissions for asthma in four European cities: the APHEA project. Thorax. 1997;52:760-5.

19. Anderson HR, et al. Air pollution and daily admissions for chronic obstructive pulmonary disease in 6 European cities: results from the APHEA project. Eur Respir J. 1997;10:1064-71.

20. Wong CM, Atkinson RW, Anderson HR, et al. A tale of two cities: effects of air pollution on hospital admissions in Hong Kong and London compared. Environ Health Perspect. 2002;110(1):67-77.

21. Dales R, et al. Air pollution and sudden infant death syndrome. Pediatrics. 2004;113:628-31.

22. Stieb DM, Judek S, Burnett RT. Meta-analysis of time-series studies of air pollution and mortality: effects of gases and particles and the influence of cause of death, age, and season. J Air Waste Manag Assoc. 2002;52:470-84.

23. Touloumi G, Katsouyanni K, Zmirou D, et al. Short-term effects of ambient oxidant exposure on mortality: a combined analysis within the APHEA project. Air pollution and health: a European approach. Am J Epidemiol. 1997;146:177-85. 
24. Katsouyanni K, Touloumi G, Samoli E, et al. Confounding and effect modification in the short-term effects of ambient particles on total mortality: results from 29 European cities within the APHEA2 project. Epidemiology. 2001;12:521-31.

25. Samet JM, Zeger SL, Dominici F, et al. The national morbidity, mortality, and air pollution study. Part II. Morbidity and mortality from air pollution in the United States. Research Report. Charlestown: Health Effects Institute; 2000, 94(2):5-79.

26. Dominici F, McDermott A, Daniels M, et al. Mortality among residents of 90 cities. Revised analyses of time-series studies of air pollution and health (Health Effects Institute Special Report). Montpelier: Capital City Press; 2003.

27. Schwartz J. Air pollution and hospital admissions for cardiovascular disease in Tucson. Epidemiology. 1997;8:371-7.

28. Galan I, et al. Short-term effects of air pollution on daily asthma emergency room admissions. Eur Respir J. 2003;22:802-8.

29. Linaker $\mathrm{CH}$, et al. Personal exposure to nitrogen dioxide and risk of airflow obstruction in asthmatic children with upper respiratory infection. Thorax. 2000;55:930-3.

30. Gryparis A, et al. Acute effects of ozone on mortality from the "Air Pollution and Health: a European Approach" project. Am J Respir Crit Care Med. 2004;170:1080-7.

31. Bell ML, Dominici F, Samet JM. A meta analysis of time-series studies of ozone and mortality with comparison to the national morbidity, mortality and air pollution study. Epidemiology. 2005;16:436-45.

32. Ito K, De Leon SF, Lippmann M. Association between ozone and daily mortality: analysis and meta-analysis. Epidemiology. 2005;16:446-57.
33. Bell ML, et al. Ozone and short-term mortality in 95 urban communities, 1987-2000. JAMA. 2004;292:2372.

34. Hong YC, Lee JT, Kim H, Kwon HJ. Air pollution: a new risk factor in ischemic stroke mortality. Stroke. 2002;33(9):2165-9.

35. Zhang Y, Huang W, London SJ, Song G, Chen G, Jiang L, Zhao N, Chen B, Kan H. Ozone and daily mortality in Shanghai, China. Environ Health Perspect. 2006;114(8):1227-32.

36. Pope CA III, Burnett RT, Thun MJ, Calle EE, Krewski D, Ito K, Thurston GD. Lung cancer, cardiopulmonary mortality, and longterm exposure to fine particular air pollution. JAMA. 2002;287:1132-41.

37. Dockery DW, Pope CA III, Xu X, Spengler JD, Ware JH, Fay ME, Ferris BG Jr, Speizer FE. An association between air pollution and mortality in six U.S. cities. $N$ Engl J Med. 1993;329(24):1753-9.

38. Miller KA, Siscovick DS, Sheppard L, Shepherd K, Sullivan JH, Anderson GL, Kaufman JD. Long-term exposure to air pollution and incidence of cardiovascular events in women. N Engl J Med. 2007;356:447-58.

39. Clancy L, Goodman P, Sinclair H, Dockery D W. Effect of airpollution control on death rates in Dublin, Ireland: an intervention study. Lancet. 2002;360:1210-4.

40. World Health Organization. Air Quality Guidelines, Global Update 2005, particulate matter, ozone, nitrogen dioxide and sulfur dioxide. Copenhagen: WHO Regional Office for Europe; 2006. 